\title{
A one-dimensional color order system for dental shade guides
}

\author{
W.J. O'Brien \\ C.L. Groh \\ K.M. Boenke \\ Department of Biologic and Materials \\ Sciences \\ School of Dentistry \\ The University of Michigan \\ Ann Arbor, Michigan 48109-1078
}

Received November 29, 1988

Accepted February 10, 1989

This investigation was supported in part by USPHS Research Grant DE05423 from the National Institute of Dental Research, National Institutes of Health, Bethesda, MD 20892.

Dent Mater 5:371-374, November, 1989

\begin{abstract}
The purpose of this study was to re-arrange the master Bioform shade guide into a long-range one-dimensional color system based upon color difference. Although most shade guides may show local order when arranged according to hue, long-range order has not been established. However, shade guide arrangement according to a logical color order would be an advantage to the user. The first step in determining the color order was to measure the color of the shade guide teeth. A methodology procedures have not always been described. The purpose of this study was (1) to develop a detailed methodology for measuring the color of dental shade guide teeth, (2) to rearrange the master Bioform shade guide into a long-range one-dimensional color order system based upon color difference, and (3) to compare this arrangement with another arrangement based upon visual perception.
\end{abstract} was developed for measuring the color by use of a reflectance spectrophotometer. The precision of measurement was determined to be equal to CIE $L^{*} a^{\star} b^{*} \Delta E$ of 0.5 . Spectra were obtained and converted into CIE $L^{\star} a^{\star} b^{\star}$ and Munsell notation. The measured colors of the Bioform shades ranged from a Munsell hue of $0.9 \mathrm{Y}$ to $3.5 \mathrm{Y}$; a value of 6.6 to 7.8 ; and a chroma of 1.9 to 4.1 . The teeth were then arranged visually from light to dark. The correlation coefficient between the visual ranking and color difference was 0.95 . There was an inverse correlation between visual ranking and Munsell value, with a correlation coefficient of 0.90 . Therefore, the sequence according to color difference provided the better agreement with visual perception.
D ental shade guides have been used for many years to identify and communicate the color desired for prosthetic appliances. Recent American Dental Association acceptance guidelines (Wozniak, 1987) have stated that "the color samples [of the dental shade guide] will be arranged according to a logical order which is explained in the directions". This task is complicated, since most color systems are three-dimensional (for example, the Munsell color system defines color in terms of hue, value, and chroma).

Although color measurements of other shade guides have been reported (Sproull, 1973; Shotwell et al., 1986; Miller, 1987), the experimental

\section{MATERIALS AND METHODS}

The spectral reflectance of the master Bioform shade guide teeth (obtained on loan from Dentsply International, Inc., York, PA) was determined by use of a dual-beam spectrophotometer (Beckman Model ACTA CIII, Beckman Instruments, Inc., Fullerton, CA). This spectrophotometer was equipped with an integrating sphere attachment (No. 198848, Model ASPH-U, Beckman Instruments, Inc.) and a beam-reducing accessory (No. 199056, Model ASPH-BR, Beckman Instruments, Inc.), which reduced the light beam to a dimension of approximately $1 \mathrm{~mm}$ $\times 8 \mathrm{~mm}$ (the sample-holder exposed a $7 \mathrm{~mm} \times 10 \mathrm{~mm}$ oval on the tooth surface). The spectrophotometer used collimated illumination at $4.5^{\circ}$ from the normal to the sample surface. The integrating sphere was used to collect the diffusely reflected radiation. These conditions are designated as $0 / d$ viewing conditions (Judd and Wyszecki, 1975). The custom-made adapter (Shotwell et al., 1986), which permitted consistent alignment of the samples to be maintained in the illuminating beam, is shown in Fig. 1 . The portion of this adapter facing the integrating sphere port was coated with barium sulfate (Baker Analyzed Reagent, lot no. 429178, J.T. Baker Chemical Co., Phillipsburg, $\mathrm{NJ})$ to maximize reflection within the sphere. The spectrophotometer was calibrated by means of a zero cone (No. 587738, Beckman Instruments, Inc.), a primary white porcelain standard (B-2 Standard, Custom Fabrication, Erie Ceramic Arts, Erie, PA), and a secondary standard consisting of a denture tooth (Bioblend $22 \mathrm{E}$ porcelain left central incisor, Dentsply International, Inc.) having a flattened labial surface and coated with an opaque white porcelain (Ceramco porcelain Paint-0-Pake white modifier, Ceramco, Inc., $\mathrm{N}$. Brunswick, NJ). The tabs were removed from the shade guide teeth, and the lingual surfaces were flattened and coated with barium sulfate.

Relative reflectance data were recorded in the range of $410 \mathrm{~nm}$ to 700 $\mathrm{nm}$ at $10-\mathrm{nm}$ intervals. Relative reflectance measurements were converted to absolute reflectance. Tristimulus coordinates were determined for each sample by use of the CIE 1931 standard observer functions and standard illuminant source C. These represent two-degree observer and noon daylight, respectively. The tristimulus coordinates were then converted to the CIE $\mathrm{L}^{*} \mathrm{a}^{*} \mathrm{~b}^{*}$ and Munsell color systems. 


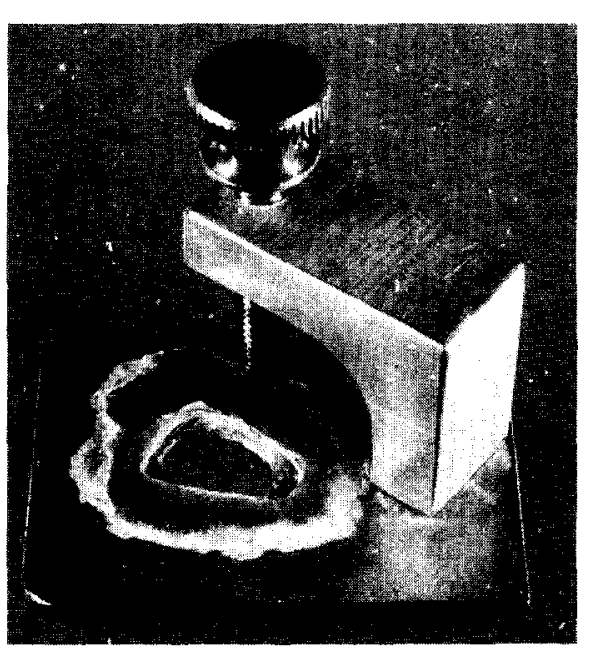

Fig. 1. The custom-adapter permilted consistent alignment of the samples to be maintained in the illuminating beam of the spectrophotometer.

The Munsell color system is a popular system for the visual determination of color and is based upon polar coordinates. In 1976, the Commission Internationale de l'Eclairage (CIE) adopted a uniform color space system based upon rectangular coordinates and designated it $\mathrm{L}^{*} \mathrm{a} * \mathrm{~b} *$. The corresponding color difference formula is:

$$
\Delta \mathrm{E}=\underset{\left.\left(\Delta \mathrm{b}^{*}\right)^{2}\right]^{1 / 2}}{\left[\left(\Delta \mathrm{a}^{*}\right)^{2}+\right.}
$$

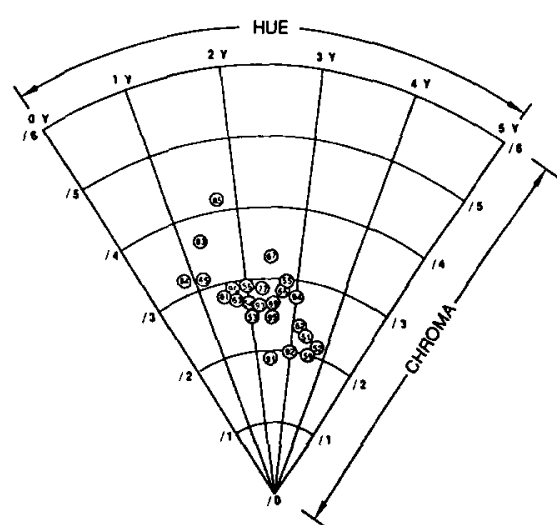

Fig. 2. A plot of the Munsell hue and chroma for the master Bioform shade guide.

where $\Delta \mathrm{L}^{*}, \Delta \mathrm{a}^{*}$, and $\Delta \mathrm{b}^{*}$ are differences in the CIE uniform color space parameters of the two colors. The CIE L*a*b* color differences were calculated from Eq. 1 for each tooth compared with B-59, the lightest shade.

We accomplished the visual ranking by arranging the shade guide teeth from light to dark, using sunlight-simulating fluorescent lamps (Vita-Lite, Duro-Test Corp., North Bergen, NJ).

\section{RESULTS}

The Munsell notation, the chroma-

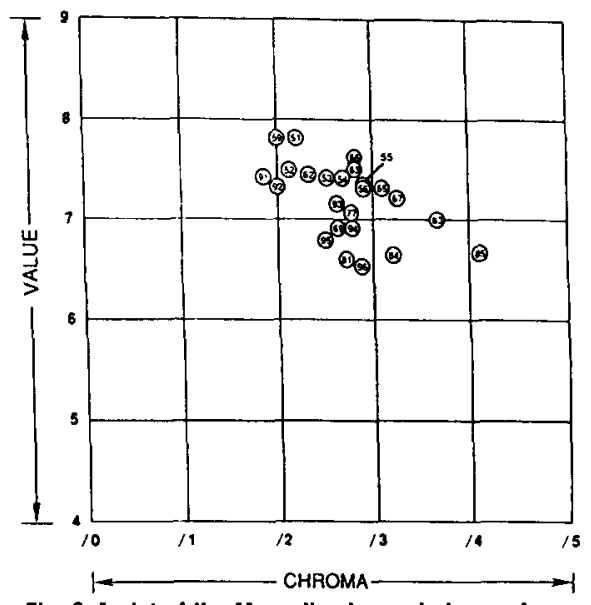

Fig. 3. A plot of the Munsell value and chroma for the master Bioform shade guide.

ticity coordinates, the CIE L*a*b* color coordinates, and the $\Delta \mathrm{E}$ of $\mathrm{B}$ 59 vs. each of the other master Bioform tabs measured are presented in Table 1. Two additional sets of measurements were made to determine the precision of the method described here. First, duplicate measurements were made of the shade guide teeth - that is, after the first set of measurements was made, all the teeth were re-measured. The $\Delta \mathrm{E}$ CIE L*a*b* was calculated from Eq. 1 for each replication. The mean $\Delta \mathrm{E}$

\begin{tabular}{|c|c|c|c|c|c|c|c|c|c|}
\hline \multirow[b]{2}{*}{ Shade } & \multicolumn{2}{|c|}{$\begin{array}{l}\text { Munsell } \\
\text { Notation }\end{array}$} & \multicolumn{3}{|c|}{$\begin{array}{l}\text { Chromaticity } \\
\text { Coordinates }\end{array}$} & \multicolumn{3}{|c|}{$L^{\star} a^{\star} b^{\star}$} & \multirow{2}{*}{$\begin{array}{l}\Delta \mathrm{EV} \\
\mathrm{B}-59\end{array}$} \\
\hline & $\mathrm{H}$ & $\begin{array}{ll}\mathrm{V} \\
\mathrm{C}\end{array}$ & $Y$ & $x$ & $y$ & $L^{*}$ & $a^{*}$ & $b^{\star}$ & \\
\hline B-59 & $3.5 Y$ & $7.80 / 2.0$ & 55.72 & 0.3407 & 0.3502 & 79.49 & -1.10 & 15.26 & 0.0 \\
\hline B-51 & $3.2 Y$ & $7.80 / 2.2$ & 55.24 & 0.3432 & 0.3525 & 79.21 & -0.99 & 16.31 & 1.09 \\
\hline B-91 & $2.4 Y$ & $7.45 / 1.9$ & 49.57 & 0.3406 & 0.3484 & 75.84 & -0.42 & 14.14 & 3.88 \\
\hline B- 62 & $3.1 Y$ & $7.45 / 2.3$ & 49.92 & 0.3454 & 0.3539 & 76.05 & -0.64 & 16.53 & 3.69 \\
\hline B- 66 & $2.8 Y$ & $7.55 / 2.8$ & 51.21 & 0.3534 & 0.3615 & 76.84 & -0.42 & 20.18 & 5.63 \\
\hline B-52 & $3.6 Y$ & $7.50 / 2.1$ & 50.42 & 0.3451 & 0.3553 & 76.36 & -1.28 & 16.94 & 3.56 \\
\hline B-53 & $2.1 Y$ & $7.40 / 2.5$ & 49.39 & 0.3499 & 0.3559 & 75.72 & 0.33 & 17.76 & 4.74 \\
\hline B-92 & $3.0 Y$ & $7.35 / 2.0$ & 48.67 & 0.3429 & 0.3514 & 75.28 & -0.66 & 15.27 & 4.23 \\
\hline B- 63 & $1.7 Y$ & $7.45 / 2.8$ & 50.00 & 0.3548 & 0.3594 & 76.10 & 0.87 & 19.64 & 5.88 \\
\hline B- 54 & $2.0 Y$ & $7.40 / 2.7$ & 49.15 & 0.3532 & 0.3589 & 75.58 & 0.46 & 19.13 & 5.72 \\
\hline B-65 & $1.1 Y$ & $7.30 / 3.1$ & 49.14 & 0.3606 & 0.3629 & 75.57 & 1.73 & 21.48 & 7.88 \\
\hline B- 93 & $2.2 Y$ & $7.15 / 2.6$ & 45.01 & 0.3526 & 0.3584 & 72.93 & 0.40 & 18.34 & 7.40 \\
\hline B-55 & $2.9 Y$ & $7.30 / 2.9$ & 47.10 & 0.3558 & 0.3639 & 74.28 & -0.39 & 20.69 & 7.56 \\
\hline B- 69 & $2.6 Y$ & $6.95 / 2.6$ & 42.49 & 0.3545 & 0.3614 & 71.24 & 0.03 & 19.11 & 9.17 \\
\hline B- 94 & $3.0 Y$ & $6.95 / 2.7$ & 42.30 & 0.3548 & 0.3627 & 71.11 & -0.32 & 19.48 & 9.41 \\
\hline B- 95 & $2.6 Y$ & $6.85 / 2.4$ & 41.22 & 0.3502 & 0.3570 & 70.36 & 0.03 & 17.07 & 9.37 \\
\hline B-67 & $2.5 Y$ & $7.20 / 3.2$ & 46.26 & 0.3614 & 0.3681 & 73.74 & 0.14 & 22.66 & 9.45 \\
\hline B-56 & $2.0 Y$ & $7.30 / 2.9$ & 47.80 & 0.3581 & 0.3633 & 74.73 & 0.66 & 21.00 & 7.66 \\
\hline B-77 & $2.3 Y$ & $7.05 / 2.8$ & 44.09 & 0.3572 & 0.3628 & 72.32 & 0.50 & 20.16 & 8.83 \\
\hline B-81 & $1.5 Y$ & $6.60 / 2.8$ & 38.82 & 0.3588 & 0.3616 & 68.65 & 1.43 & 19.24 & 11.82 \\
\hline B-96 & $1.9 Y$ & $6.55 / 2.9$ & 37.05 & 0.3610 & 0.3641 & 67.34 & 1.31 & 19.93 & 13.24 \\
\hline B-83 & $1.3 Y$ & $7.00 / 3.6$ & 43.25 & 0.3693 & 0.3701 & 71.52 & 2.25 & 23.94 & 12.25 \\
\hline B. 84 & $0.9 Y$ & $6.65 / 3.2$ & 37.98 & 0.3663 & 0.3653 & 68.01 & 2.74 & 21.21 & 13.49 \\
\hline B- 85 & $1.8 \mathrm{Y}$ & $6.65 / 4.1$ & 38.24 & 0.3811 & 0.3794 & 68.23 & 2.91 & 27.38 & 17.02 \\
\hline
\end{tabular}
for all shades was 0.49 , with a stan- 
dard deviation of 0.33 for the 24 teeth. A second estimate of precision was obtained by measurement of a single shade guide tooth (shade 62) 20 times. The means for $L^{*}, a^{*}$, and $b^{*}$ were calculated for the 20 measurements and the $\Delta \mathrm{E}$ calculated between each measurement and the mean values. The precision of the 20 measurements was 0.50 , with a standard deviation of 0.29 . The second estimate confirmed the first, with an average precision of 0.50 .

A plot of the Munsell hue and chroma for the shade tabs is shown in Fig. 2. The hues range from 0.9 $\mathrm{Y}$ (shade 84 ) to $3.5 \mathrm{Y}$ (shade 52). The chromas range from 1.9 (shade 91) to 4.1 (shade 85 ).

A plot of value and chroma is shown in Fig. 3. The values range from 6.6 (shade 96) to 7.8 (shades 59 and 51).

The correlation of $\Delta E$ CIE L*a*b* with visual ranking is shown in Fig. 4. The linear regression equation is:

$$
y=0.773+0.548 x
$$

with a correlation coefficient of 0.95 .

The correlation of Munsell value with visual ranking is shown in Fig. 5. The linear regression equation is:

$$
\mathrm{y}=7.761-0.045 \mathrm{x}
$$

with a correlation coefficient of 0.90 .

Two arrangements for the Bioform shade guide are shown in Fig. 6 . The top row is the regular arrangement with no long-range order, and the bottom row is arranged by visual ranking.

\section{DISCUSSION}

The color of the Bioform shade guide was determined in this study. Previously, results were reported graphically by Sproull (1973) and Miller (1987) on the color of this shade guide (see Table 2). A comparison between the results of these studies was done with the Nickerson (1936) color difference formula:

$$
\begin{aligned}
\mathrm{I}=(2 / 5) \mathrm{C}_{\mathrm{av}} \Delta \mathrm{H} \\
+6 \Delta \mathrm{V}+3 \Delta \mathrm{C}
\end{aligned}
$$

where $\mathrm{C}_{\mathrm{av}}$ is the average chroma, and $\Delta \mathrm{H}, \Delta \mathrm{V}$, and $\Delta \mathrm{C}$ are differences in hue, value, and chroma of the two colors being compared. The mean color difference, I, between the results of this study and those of Sproull and Miller was calculated to be 4.98

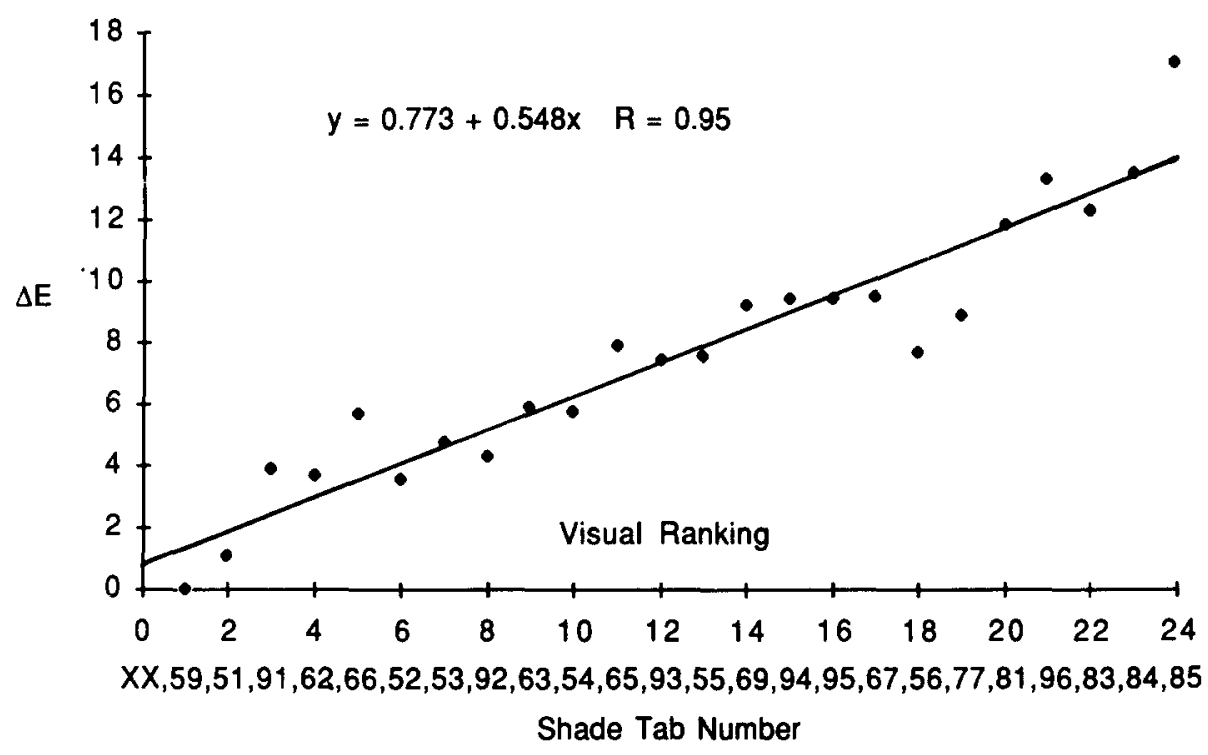

Fig. 4. The correlation of $\Delta E$ CIE $L^{*} a^{*} b^{*}$ with visual ranking.

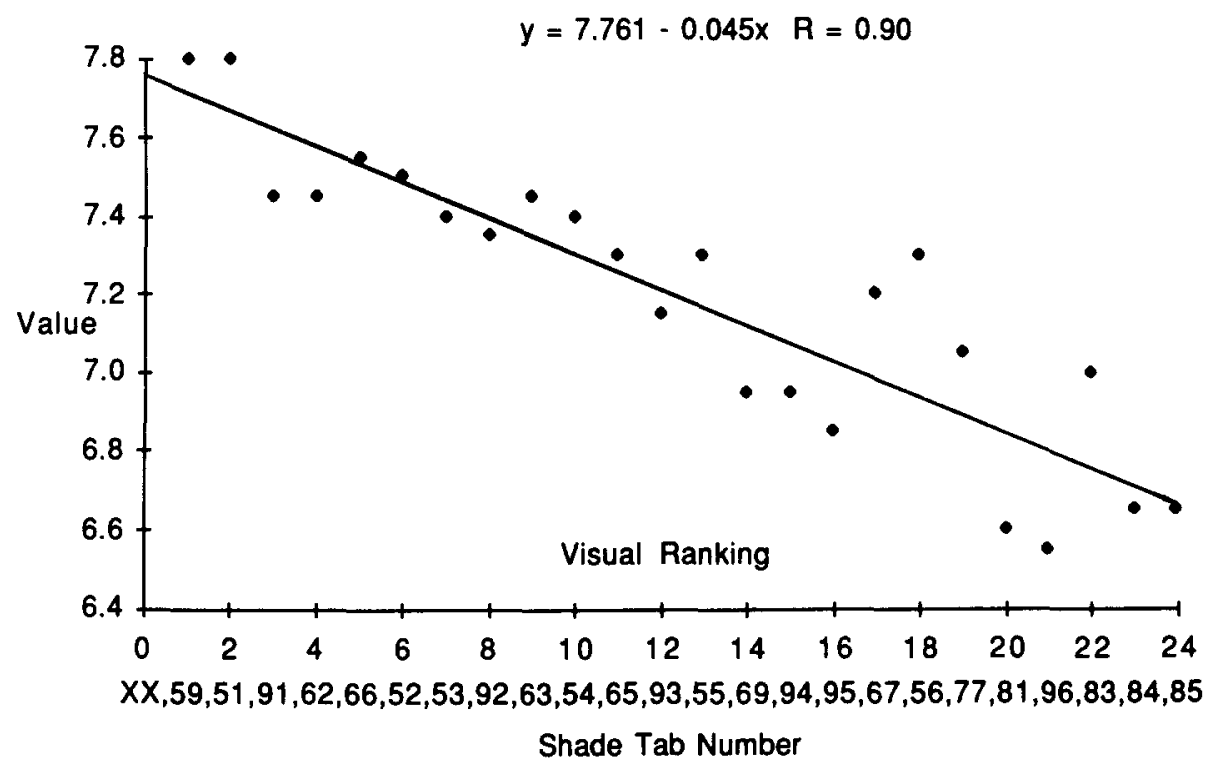

Fig. 5. The correlation of Munsell value with visual ranking.

and 3.36 , respectively. These are significant color differences which are likely to be perceived by most observers. There are three likely sources of these differences. First is the interpretation of the graphical results. Second, there is likely to be sample-to-sample variation. In the present study, a master shade guide standard from the manufacturer was used rather than production samples. A third probable source of the difference is in the measurement procedure. In this study, a barium sulfate coating was used, since the samples were translucent. The experimental procedures used in the other studies were not described, and therefore possible differences cannot be identified.

The arrangement of the shade guide according to color difference from light to dark provides a means of giving a one-dimensional color order system to a dental shade guide. The use of Munsell color notation and a color order could be the first step in improving dental shade guides.

\section{CONCLUSIONS}

A method has been presented for the measurement of translucent porcelain shade guide samples, since routine measurements will be necessary under the American Dental Association acceptance program. Methods 
TABLE 2

COMPARISON OF MUNSELL NOTATION FOR BIOFORM SHADE GUIDES REPORTED BY THREE DIFFERENT AUTHORS

\begin{tabular}{llllll}
\hline & & $\mathrm{n}$ & Hue & Value & Chroma \\
\hline O'Brien & $1989^{*}$ & 24 & $0.9 Y-3.5 Y$ & $6.6 /-7.8 /$ & $/ 1.9-/ 4.1$ \\
Miller & 1987 & 24 & $1.1 Y-3.7 Y$ & $6.7 /-7.95 /$ & $12.2-/ 4.8$ \\
Sproull & 1973 & 12 & $8.9 Y R-3.8 Y$ & $6.8 /-8.05 /$ & $/ 2.8-/ 4.8$ \\
\hline
\end{tabular}

${ }^{\star}$ Results presented in this paper.

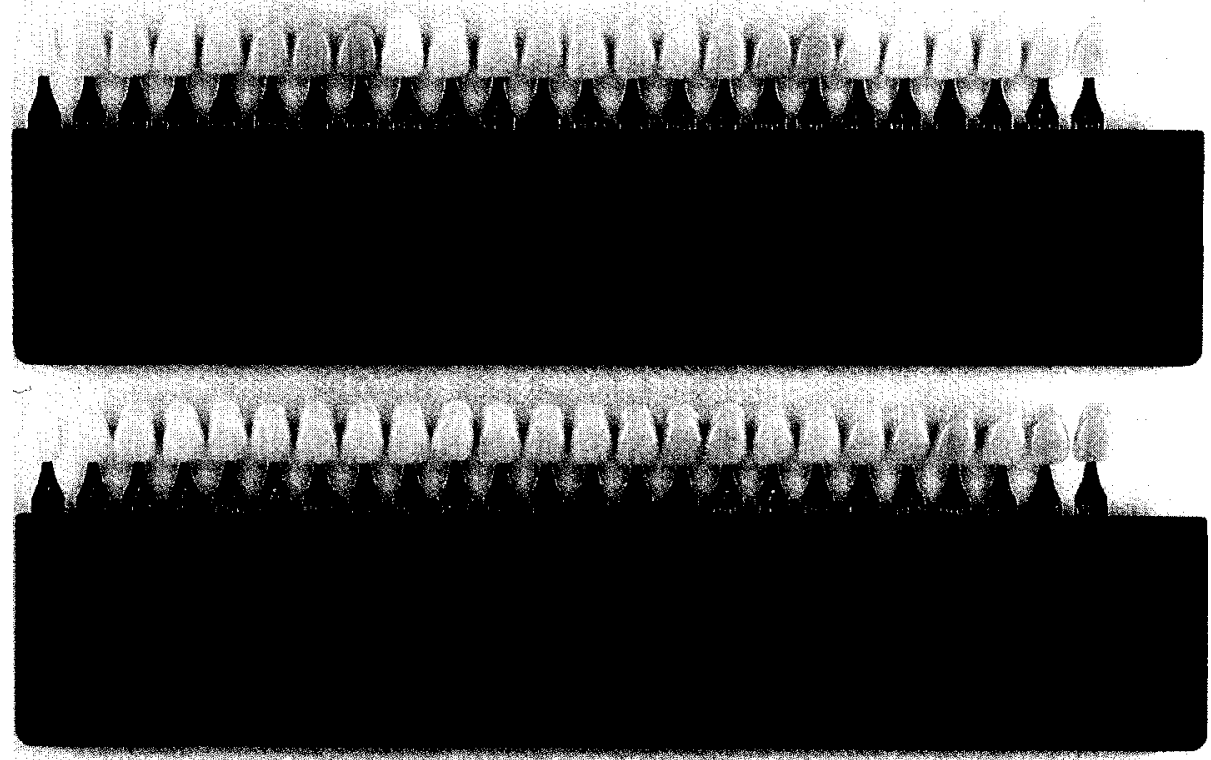

Fig. 6. Two arrangements for the Bioform shade guide. The top row is the regular amangement with no longrange order, and the bottom row is amanged by visual ranking.

for color measurement need to be carefully described. Results are very sensitive to methods employed when any energy measurements are made. Also, the precision of any method needs to be determined. A detailed methodology is presented here for the measurement of the color of shade production. The next step in this program is to determine shade guide sample variation.

The proposed arrangement according to color difference is a good correlation with the visual arrangement. It will not be perfect, since the teeth are layered and the color varies across the surface of the tooth for a natural appearance.

\section{ACKNOWLEDGMENTS}

This paper was originally presented at the 66th General Session of the International Association for Dental Research, 1988.

The authors wish to thank Dentsply International, Inc., for the loan of the master Bioform shade guide.

\section{REFERENCES}

BECKMAN INSTRUMENTS (1977): Installation Instructions for 198848 and 198851 Integrating Spheres, Fullerton, CA: Beckman Instruments, Inc., p. 10.

JUDD, D.B. and WYSZECKI, G. (1975): Color in Business, Science and Industry, 3rd ed., New York: John Wiley and Sons.

MILleR, L. (1987): Organizing Color in Dentistry, $J A m$ Dent Assoc (Sp Iss): $26 \mathrm{E}-40 \mathrm{E}$.

Nickerson, D. (1936): The Specification of Color Tolerances, Textile Res 6: 505514.

ShotWell, J.L.; Johnston, W.M.; and SwarTZ, R.G. (1986): Color Comparisons of Denture Teeth and Shade Guides, $J$ Prosthet Dent 56: 31-34.

Sproull, R.C. (1973): Color Matching in Dentistry. Part II. Practical Applications of the Organization of Color, $J$ Prosthet Dent 29: 556-566.

WoznIaK, W.T. (1987): Proposed Guidelines for the Acceptance Program for Dental Shade Guides, Chicago: American Dental Association. 